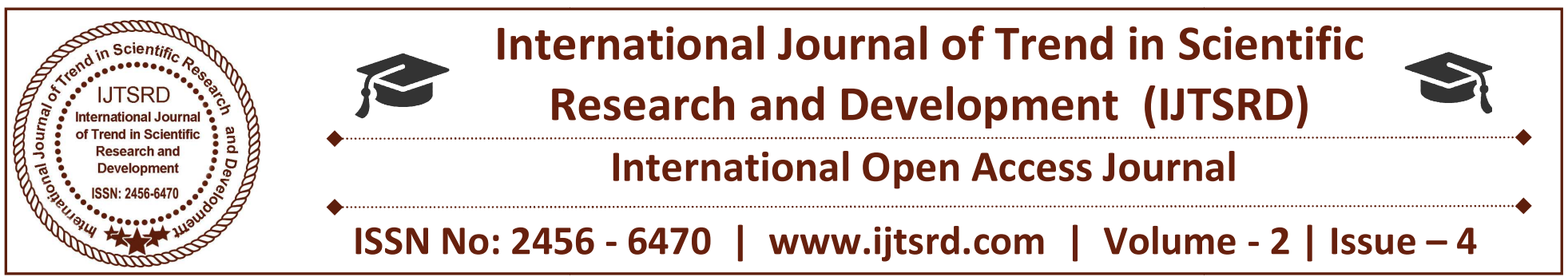

\title{
Barriers and Opportunities of Inclusive Education in Present Educational System
}

\author{
Dr. Mita Howladar \\ Assistant Professor, Calcutta Girls' B. T. College, \\ Kolkata, West Bengal, India
}

\begin{abstract}
Inclusive education allows for universal inclusion, participation and achievement of all children, including children with specific learning difficulties. Children form a heterogeneous group with diverse cognitive deficits, special educational needs and strengths, and have a legislated right to the continuum of both assistance and support programmes for all level education system. The goal is to eliminate all barriers in order to achieve learning on individual goals while participating in the life of the classroom with other students by their own age. But this conception and out coming at present scenario by this process is not successful because there is some problem arises for inclusive education such as disability, gender, emotional/ behavioral problems, family background, ethnicity, giftedness, migrants, poverty, hearing or visual impairment, language delay, among others. There is some positive implementation of inclusive learning, teaching and assessment strategies. Teachers should keep in mind that these outcomes apply to all and access to general schools for people with disabilities is an advance in the education. However, barriers to learning and participation hinder the school routine of inclusive students, hence the need for resources - human, tangible, political etc. from the schools, parents, families and their communities.
\end{abstract}

Keywords: Inclusive Education, Barriers, Resources, Education System

\section{INTRODUCTION}

The inclusive education is an important pathway in educational developmental system with a strong commitment to his / her community and nation. It

needs to move on the basis of capability, intellectual power and other suitable physical, psychological and environment condition.

The inclusive education at present is taking as 'wholeschool' approach to institutional change (Peters, 2004), and influenced by the social model of disability. Children in spectal schools were seen as geographically and socially segregated from their peers, and the initial movement to locationally integrate these students in mainstream schools ('integration') shifted to one where the whole school was encouraged to become more adaptable and inclusive it its day-to-day education practices for all students ('inclusive education'). Pedagogy in particular was highlighted as the key to meeting all students' educational needs by making the curriculum flexible, and so more accessible. By recognising that teaching methods which can make curriculum accessible to children with disabilities can also make learning accessible to all students (Ainscow, 2005; Ainscow, 1991), a teacher or school principal is well on the way to improving the overall quality of their school. In this way, inclusive education is not a disability-only issue, but an educational quality issue.

Inclusive education is more effective in the present educational system and it is more ensuring proper provision for children with special educational needs but it depends on the costs to schools, pupils and disability, gender, emotional / behavioural problems, family background, ethnicity, giftedness, migrants, poverty hearing or or visual impairment, language delay, among others. Negative and harmful attitudes towards difference in our society remain critical 
barriers to learning and development. There is a growing consensus that people with disabilities should be included in development programmes. However, if a person with a disability is dehumanised by cultural belief or stigma, as they are in India (Alur, 2002), then they can be 'invisibilised' and not considered worthy of rights. Inclusive education reflect the relationships among the social, political, economic, cultural and historical contexts that are present at any one time in a particular country and / or local authority but not properly improve and success among the different situation and community. It should be embedded in a series of ways such as parent, the family, the school and to the classroom, the local community and extending to the broad society. It generally works positively at the primary school level, but serious problems emerge at the secondary and onwards level. This was attributed to increased gap between the teaching-learning pattern and achievement of students with age. This discourse is attempting to shift perceptions of disability from the medical model to the social model. However, there are many conceptual difficulties with the terms of integration and inclusion in India, which are often used interchangeably.

Inclusive education clearly has the potential to improve teaching and learning processes for all children as well as fulfilling their rights, for the purposes of this paper we will be looking at inclusive education mostly in terms of access for children with disabilities in India due to their 'invisibilisation' "All children / students are educated in an age-appropriate, mainstream classroom in neighbourhood schools and the supports provided, so that children / students, teachers and classrooms can be successful".

$>$ The goal of inclusion in education is to eliminate by the different types of barriers with the quality and equity of education for all.

$>$ This is a big challenge for all but, it is an opportunity to advance the school as a change factor that promotes dialogue and participation, making possible well-being through an education of quality for all without exception, for the commitment of the community.

To develop and improve different types of remedial way for the equilibrium and equity of inclusive education for our nation.

Inclusion in education for all learners is very important but in present scenario it is difficult by the some arising problems in educational system. Barriers to learning and development should be addressed in our classrooms and schools. Amongst the more frequent courses of barriers are given below :

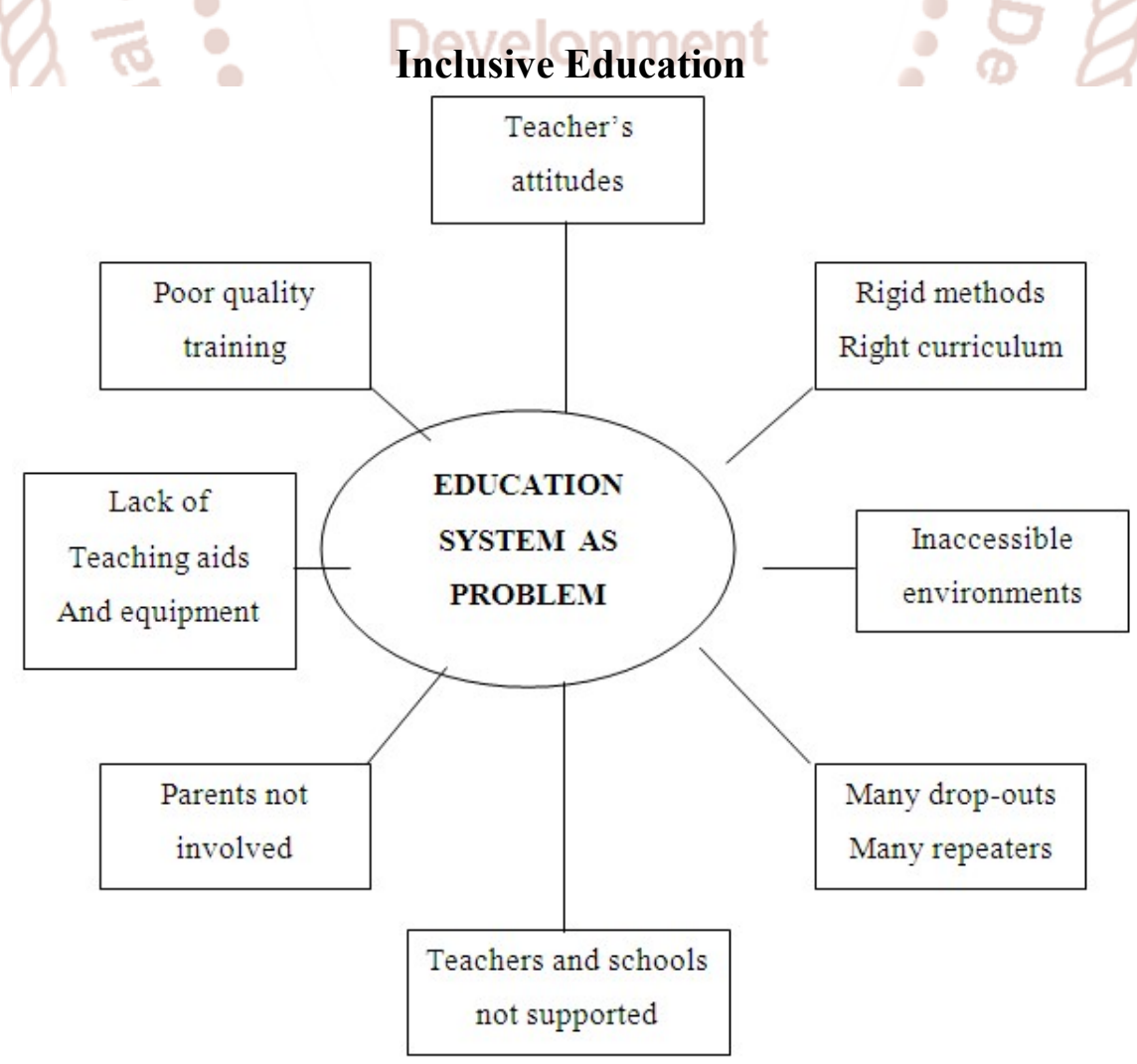

Fig. 1. Different types of problems in educational system 
It has been seen that language and the impact on children's participation and achievement in education. The use of, and teaching of, language is a complex issue for inclusive education. Communication is essential for learning and issue for inclusive education. Communication is essential for learning and development in both formal and informal aspects. Learners who are non-speaking due to the severity of their physical, intellectual and / or mental disability experience enormous barriers to learning and development. These barriers arise from the general unavailability of augmentative and alternative communication strategies to enable them to engage in the learning process, and more often than not find themselves totally excluded from learning and development experiences. This systems could consist of alternative communications systems, supplements to vocal communication and communication through facilitators. Not only does poor provision in this area lead to a dearth of necessary skills and knowledge but it also contributes to a system which is unable to meet a diversity of learner needs and prevent barriers to learning and development.

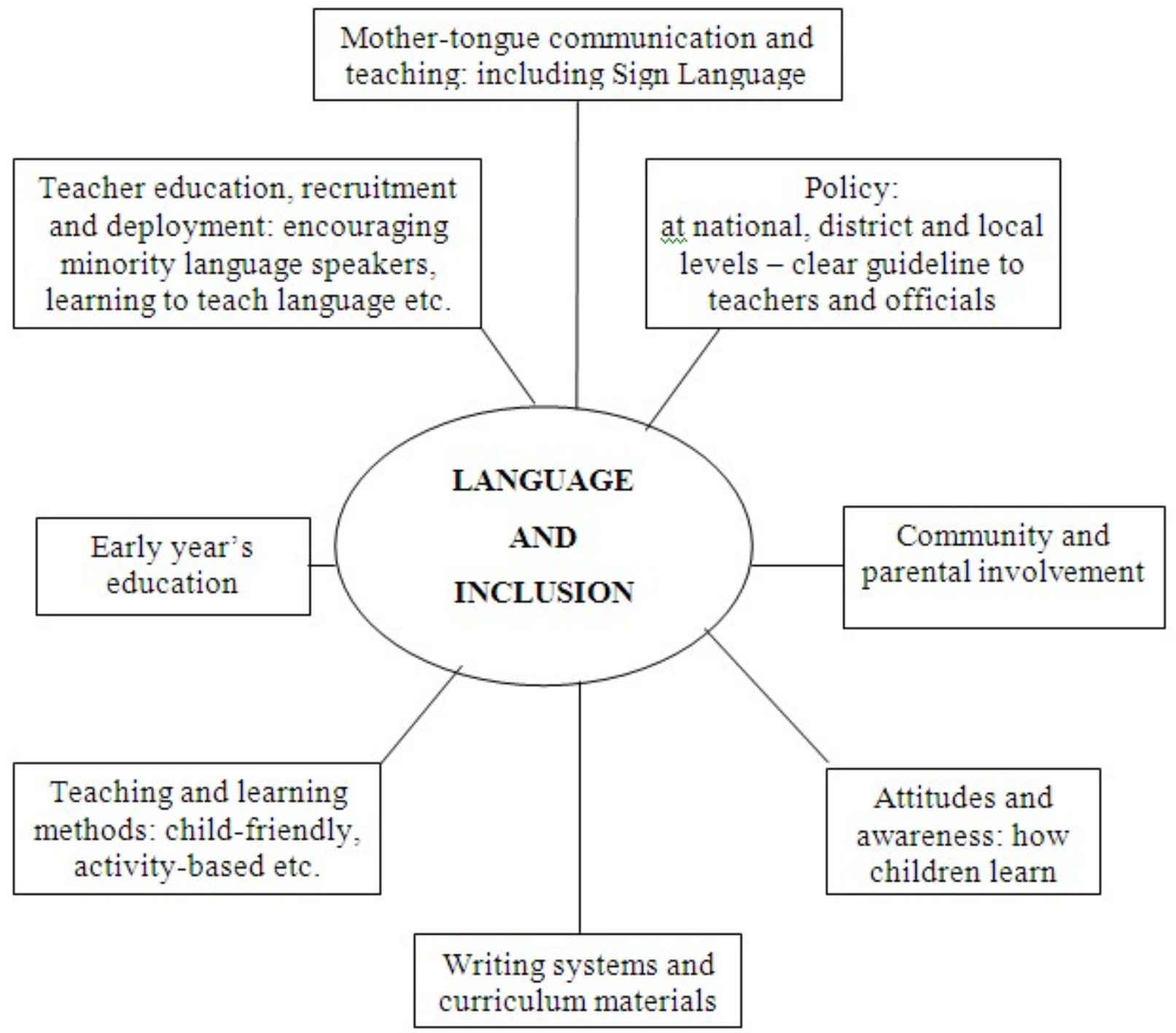

\section{Disability as a Barrier}

Fig. 2. Key issues to consider in relation to language and education (Helen Pinnock and Samantha Ross Hepworth)
Disability is a barrier to learning in various ways such as hearing impairment, minor speech impairment, mild learning difficulties, epilepsy, lack of limbs, short stature, gross obesity, autism, mental health issues and psychological barrier, eating disorder, visual barriers, hearing impairment, oral barriers and also other medical barriers which are important hindrances of teaching-learning process. Auditory barriers are an increasing awareness that a high level of performance in the traditional academic areas of mathematics, reading and language is not sufficient to ensure successful adult adjustment and that success in inclusive settings needs to be defined not only in erms of communication skills and academic achievement 
but also relation to the social development of the child with hearing loss (Ross, 1990; Schwartz, 1990). Hearing loss present at birth or occurring in early childhood often represents a significant barrier to the natural acquisition, development and use of spoken language. The degree of hearing loss as well as any delay in fitting the child with appropriate amplification are two important factors that impact directly on spoken language acquisition. The resulting language delay often found in children with hearing loss has been seen as an underlying cause of reduced academic performance (Moores, 2011). Cognitive barriers is an important issue for inclusive educator. The focus is usually on using and developing basic cognitive processes to improve skills in information storage, processing, organizing and retrieval. This may be at a phonological processing level, word level, or sentence level. Other related perspectives include different models of auditory memory, and approaches that examine how different aspects of language are stored and called up when needed.

\section{Inadequate Opportunity for Program me-to-work Linkages}

Learners with cognitive barriers, age constraints and social barriers, need specific programme-to-work linkages. Certification for the level of skills achieved need recognition to facilitate life long learning. A lack of partnerships between education and institutional environment block to learners. Appropriate accreditation and certification for the level of skills achieved need recognition to facilitate life long learning. A lack of partnerships between education and industry which would facilitate job accessibility could be a stumbling block to learners.

\section{Socio-economic Barriers}

The relationship between education provision and the socio-economic conditions in any society must be very important issue. Effective learning is fundamentally influenced by the availability of educational resources to meet the needs of any society. In many countries, especially our own country, there are inadequate numbers of centers of learning and other facilities to meet the educational needs of the population. In most cases, inadequacies in provision are linked to other inequalities in the society such as urban / rural disparities, as well as inequalities arising from discrimination on grounds such as gender, race and disability. Poor self-image children often experience social isolation and developmental deprivation. Sensory deprivation, resulting from a lack of opportunities during early childhood to explore the environment and wider world.

\section{Lack of Parental Recognition and Involvement}

Parents are not always adequately informed of their children's problems or progress, and therefore are often deprived of the opportunity to participate in their children's development. Parental involvement refers to a broad range of activities as indicated earlier. Understanding the impact of various forms of spontaneous involvement and of the large range of intervention studies on achievement. The extent and form of parental involvement is strongly influenced by family social class, maternal level of education, material deprivation, maternal psycho-social health and single parent status and to a lesser degree, by family ethnicity. The extent of parental involvement diminishes as the child gets older and is strongly influenced at all ages by the child characteristically taking a very active mediating role. Parental involvement is strongly positively influenced by the child's level of attainment: the higher the level of attainment, the more parents get involved. Adjustment must proceed in recognition of all the many factors which impinge on school outcomes. Parenting involvement provides housing, health, nutrition, safety, parenting skills in parent-child interactions: home condition to support study; information to help schools know child educational psychological achievement adjustment parental material, parental school involvement, deprivation, aspirations, composition family social class etc. York et al. (2011).

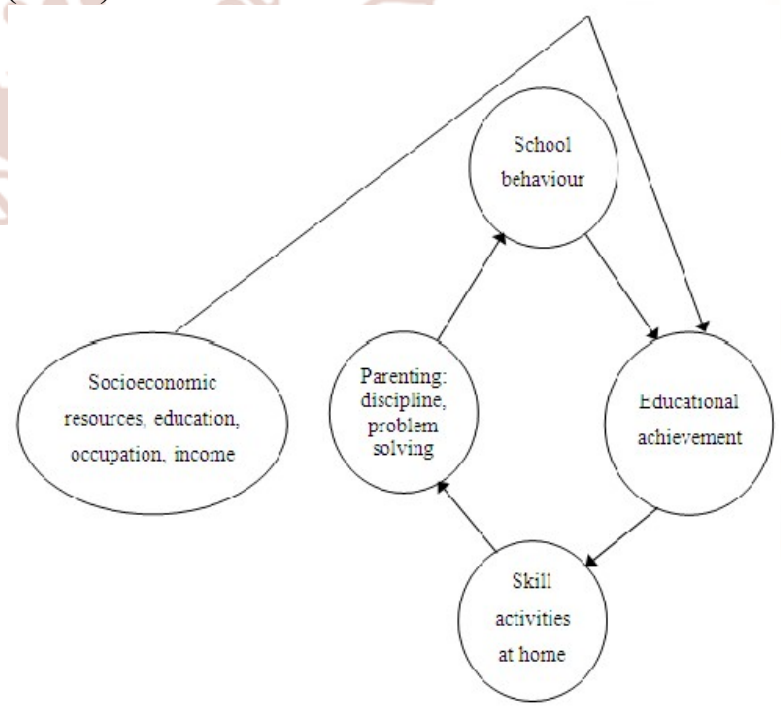

Fig. 3. Sacker et al. (2002) model of the relationship between socioeconomic status, family and educational achievement 


\section{Attitudes}

The greatest barriers to inclusion are caused by society, not by particular medical impairments. Negative attitudes towards differences result in discrimination and can lead to a serious barrier to learning. Negative attitudes can take the form of social discrimination, lack of awareness and traditional prejudices. Regarding disabled children some regions still maintain established beliefs that educating the disabled is pointless. Often the problem is identified as being caused by the child's differences rather than the education systems shortcomings. The negative attitudes are harmful attitudes towards difference in our society remain critical barriers to learning and development. Different types of barriers such as race, class, gender, culture, disability, religion, ability, sexual preference and other characteristics manifest negative attitudes towards learners in the education system.

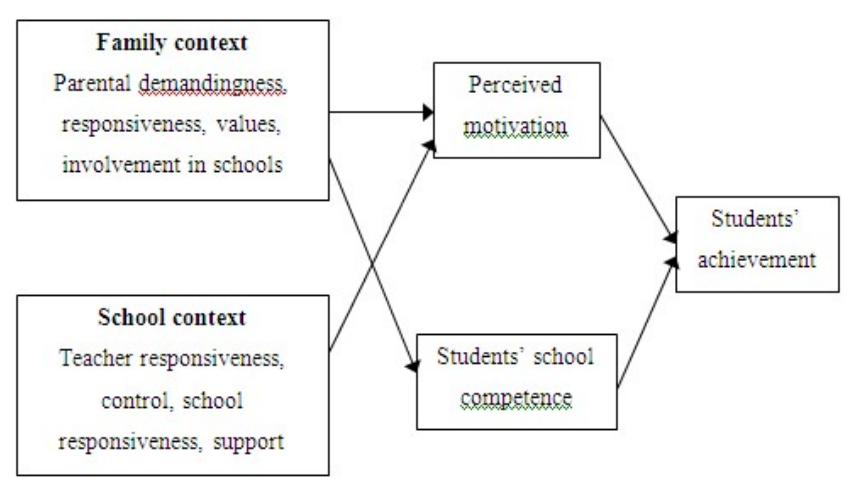

Fig. 4. Proposed relations between family and school context variables and students' achievement (De Garmo et al., 1999)

\section{Opportunities of Inclusive Education :}

Inclusive education is about appreciating each individual's differences and unique set of strengths and limitations. It's not just an education philosophy; it's an important life skill. Children grow into adults who live in a world filled with people different from themselves; learning how to interact and work with these people is a key accomplishment of childhood, as integral as academic proficiency. An inclusive school is a perfect training ground for real life with the following ways

\section{Greater Sensitivity:}

Children who develop in a typical manner become more sensitive by learning side-by-side with special needs children. They understand how words can hurt, they practice patience, and they learn empathy.

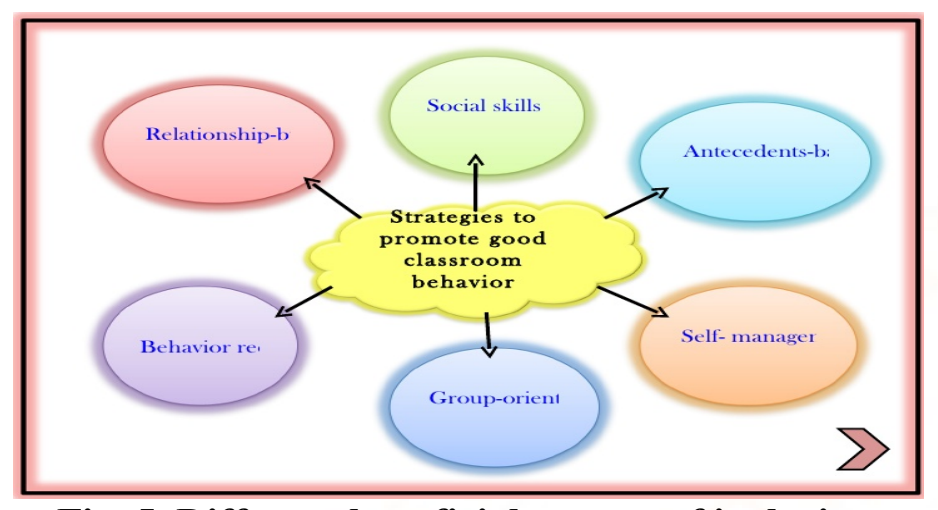

Fig. 5. Different beneficial aspects of inclusive education

\section{Better Understanding of Strengths/ Weaknesses}

Kids in inclusive schools learn that everyone has strengths and weaknesses. They learn to appreciate these differences and how to collaborate in order to accomplish something.

\section{More Tolerance}

Inclusive schooling teaches kids the value of another human being no matter what that person looks or sounds like.

\section{Spotting the Inclusive School}

Inclusive education in the real world requires a delicate balance of resources, goodwill and monitoring in order to make the experience successful and beneficial for all students.

\section{Living an Inclusive Life}

Inclusion isn't just an educational style, it's a life philosophy. Children pick up cues from adults early on, and if you make a big deal of people's differences, your children will, too. Inclusive education combats the world's tendency toward prejudice and fear, and produces more tolerant, peaceful, and open children and adults.

\section{Families' Visions of a Typical Life for their Children CanCome True}

All parents want their children to be accepted by their peers, have friends and lead "regular" lives. Inclusive settings can make this vision a reality for many children with disabilities.

\section{Children Develop a Positive Understanding of Themselves and Others}

When children attend classes that reflect the similarities and differences of people in the real world, they learn to appreciate diversity. Respect and 
understanding grow when children of differing abilities and cultures play and learn together.

\section{Friendships Develop}

Schools are important places for children to develop friendships and learn social skills. Children with and without disabilities learn with and from each other in inclusive classes.

\section{Children Learn Important Academic Skills}

In inclusive classrooms, children with and without disabilities are expected to learn to read, write and do math. With higher expectations and good instruction children with disabilities learn academic skills.

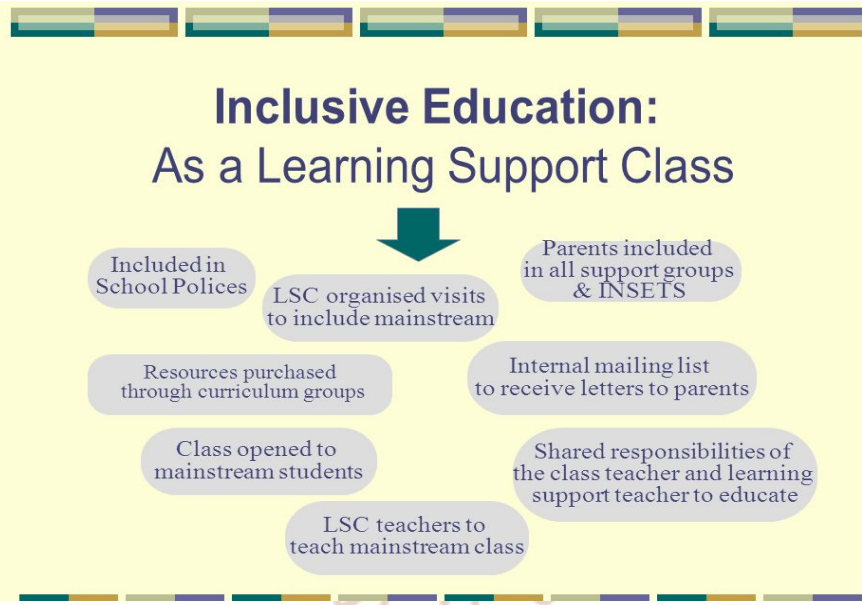

Fig. 6. Different supportive system of Inclusive Education

\section{All Children Learn by Being Together}

Because the philosophy of inclusive education is aimed at helping all children learn, everyone in the class benefits. Children learn at their own pace and style within a nurturing learning environment.

\section{Social Advantages}

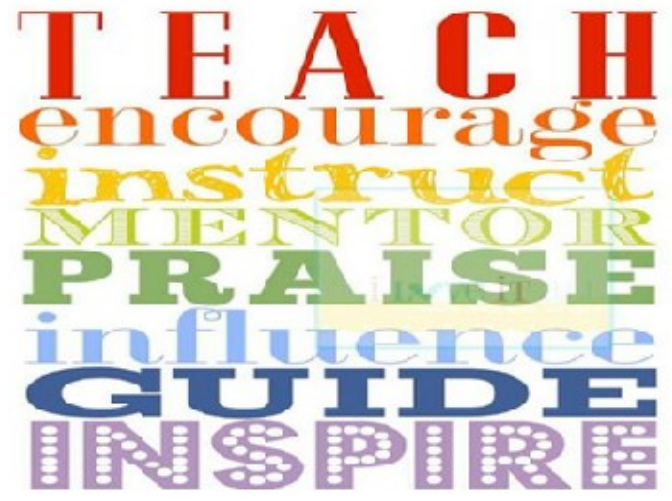

Fig 7. Social outcomes of inclusive education

One of the most obvious advantages of inclusion is the fact that students with disabilities can be integrated socially with their peers. They can create long-lasting friendships that would not be otherwise possible, and these friendships can give them the skills to navigate social relationships later on in life. Their peers can act as role models for social skills through their interactions with each other, whereas in a homogeneous. classroom, their only role models would be students with disabilities who may lack the same social skills that they do. This is especially true for more severely disabled students who would be placed in a setting with students who have little or no social interaction. By learning in an inclusive classroom instead, they are exposed to non-disabled students interacting in a normal social manner.

\section{CONCLUSION}

Inclusive education is one of the most important issues in the education system. The concept of inclusive education has been broadened to encompass not only students with disabilities, but also all students who may be disadvantaged. It is a basic human right to overcome difficulties of learning. In designing educational programmes for students with disabilities, the focus must shift from the individual's impairment to the social context. Since there is no clear demarcation between the characteristics of students with and without disabilities. The purpose and form of inclusive education reflect the relationships among the social, political, economic, cultural and historical contexts. The evidence for inclusive education is mixed but generally positive, the majority of studies reporting either positive effects or no differences for inclusion, compared with more segregated provisions. Inclusive education goes far beyond the physical placement of children with disabilities in general classrooms.

The inclusive teacher is professional educator committed to his / her community, who recognizes individual differences and considers them in his / her educational intervention actions. S/he participates in collective teaching because it is essential for collaboration and dialogue and is also creative in implementing education by facing the challenges of diversity in specific educational project interventions. In order to illustrate the individual differences in the classroom, the author follows a tridimensional view. Every inclusive teacher needs to move among these three realities in his / her classroom - seeing his / herself as being like all others, also like some others and finally, in some ways unique. This idea allows coteaching or concurrent participation. Inclusion 
promotes co-operation in the classroom. I believe this representation helps us to understand the diversity concept as well.

The collaborative work among educators facilitates inclusion and needs to be promoted in the Teacher Preparation Programme. The author believes that inclusion is funded on a collective of teachers, a team sharing knowledge, making decisions, solving problems together and generating actions to order to improve the school and to increase the learning for all. Contextual preparation connecting with the educational services, allowing identification of diversity as an enriching element has three great steps outlined below. For teachers to promote inclusive education, their training should link directly with the educational services in so called contextual professional practice. This approach, in our experience, must be presented to all throughout the training process structuring with multi-directional flow between theoretical and experiences close to educational field. So we realize that persons with disabilities are not excluded from the general education system on the basis of disability and that children with disabilities are not excluded from free and compulsory primary education, or from secondary education and ........... higher educational systems and realize that education for all to all levels.

\section{REFERENCES}

1. Ainscow, M. (1991). Effective Schools for All, London: David Fulton Publishers.

2. Ainscow, M. (2005). From Special Education to Effective Schools for All. Key.... presentation at the Inclusive and Supportive Education Congress 2005, University of Strathclyde, Glasgow.

3. Allred, K. W. (2014). Engaging parents of students with disabilities: Moving beyond the grief model. Improving Schools, 1, 1-10. Retrievedfrom http://imp.sagepub.com/cgi/doi/10. $1177 / 1365480214553745$.

4. Alur, M. (2002). Introduction in Hegarty, S. \& Alur M. (eds.) (2002) Education and Children with Special Needs: from Segregation to Inclusion. New Delhi: Sage Publications.

5. Armstrong, F. (2003). Spaced out: Policy, Difference and the Challenge of Inclusive Education, Netherlands, Kluwer Academic Publishers.
6. Ball, S. (2008). The Education Debate, Bristol, Policy Press.

7. Blachman, B. A., Ball, E., Black, R., \& Tangel, D. (1994). Kindergarten teachers develop phoneme awareness in low-income, inner-city classrooms: Does it make difference? Reading and writing: $A n$ Interdisciplinary Journal, 6, 1-17.

8. Cane, F. E., \& Oland, L. (2014). Evaluating the outcomes and implementation of a TaMHS (Targeting Mental Health in Schools) project in four West Midlands (UK) schools using activity theory. Educational Psychology in Practice, 31, $1-20$.

9. Collie, R. J., Shapka, J. D., \& Perry, N. E. (2012). School climate and social-emotional learning: Predicting teacher stress, job satisfaction, and efficacy. Journal of Educational Psychology, 104, 1189-1204.

10. Colwill, I. and Peacey, N. (2001). Planning, Teaching and Assessing the Curriculum for Pupils with Learning Difficulties: Curriculum Guidelines to support the Revised National Curriculum. British Journal of Special Education, 28(3), $120-122$.

11. Cooper, P. (2001). We Can Work It Out : What Works in Education for Pupils with Social, Emotional and Behavioural Difficulties Outside Mainstream Classrooms ? Essex: Barnardo's.

12. Davis, A., Solberg, S., deBaca, C., \& Gore, T. (2014). Use of social emotional learning skills to predict future academic success and progress toward graduation. Journal of Education for Students Placed at Risk, 19(3-4), 169-182.

13. DeGarmo, D. S. Forgatch, M. S., Martinez, C. R. (1999). Parenting of divorced mothers as a link between social status and boys' academic outcomes: Unpacking the effects of socioeconomic status, Child Development. 70(5), $1231-1245$.

14. Göransson, K., \& Nilholm, C. (2014) Conceptual diversities and empirical shortcomings - a critical analysis of research on inclusive education. European Journal of Special Needs Education, 29(3), 265-280.

15. Gulle, K. M. (2007). Teaching paraprofessionals how to write and implement social stories for students with Autism spectrum disorders. Remedial and Special Education, 28, 182 - 189. 
16. Haergerich, T. \& Metz, E. (2009). The social and character development research program: Development, goals, and opportunities. Journal of Research in Character Development, 7(2), 1-20.

17. Lipsky, D. K. and Garther, A. (1998). Factors for successful inclusion: learning from the past, looking toward the future. In S. J. Vitello and D. E. Mithuag (eds.) Inclusive schooling. National and international perspectives. New Jersey : Lawrence Erlbaum Associates.

18. Marchant, G. J., Paulson, S. E. and Rothlisberg, B. A. (2001). Relations of middle school students' perceptions of family and school contexts with academic achievement. Psychology in the Schools. $38(6), 505-519$.

19. Moore, W. and Hammond, L. (2011). Using education assistants to help pave the road to literacy: Supporting oral language, letter-sound knowledge and phonemic awareness in the preprimary year. Australian Journal of Learning Difficulties, 16(2), 85-110.

20. Nelson, H. J., Kendall, G. E., \& Shields, L. (2013). Neurological and biological foundations of children's social and emotional development: An integrated literature review. The Journal of School Nursing, 30(4), 240-250

21. Ottmar, E. R., Rimm-Kaufman, S. E., Larsen, R. A., \& Berry, R. Q. (2015). Mathematical knowledge for teaching, standards-based mathematics teaching practices, and student achievement in the context of the responsive classroom approach. American Educational Research Journal, 52(4).

22. Peters, S. (20040. Inclusive Education: An EFA Strategy for All Children, Washington DC: World Bank Root, R. W. and Reanick, R. J. (2003). An update on the diagnosis and treatment of attention deficit / hyperactivity disorder children. Professional Psychology: Research and Practice, 34(1), $34-41$.

23. Rooks, C. V., Scott, K. L., Broll, R., Zwarych, S., Hughes, R., \& Wolfe, D. A. (2015). Does an evidence-based healthy relationships program for 9th graders show similar effects for 7 th and 8th graders? Results from 57 schools randomized to intervention. Health Education Research, 30(3), $1-7$. Find this resource:
24. Shyman, E. (2015). Toward a globally sensitive definition of inclusive education based in social justice. International Journal of Disability, Development, and Education, 62(4), 351-362.

25. UNESCO, A guide for ensuring inclusion and equity in education, UNESCO, Paris, 2017.

26. UNESCO, Inclusion in education, no-date $b$, http://en.unesco.org/themes/inclusion-ineducation (Last accessed September 2017).

27. UNESCO, Introducing UNESCO, no date-a, http://en.unesco.org/about-us/introducingunesco (Last accessed September 2017).

28. United Nations, Convention on the Rights of Persons with Disabilities, United Nations, New York, 2006 , www.un.org/development/desa/disabilities/conven tion-on-the-rightsof-persons-withdisabilities/convention-on-the-rights-of-personswith-disabilities- 2.html (Last accessed September 2017).

29. United Nations, Sustainable Development Goals. Goal Irn4: Quality Education, 2015, www.undp.org/content/undp/en/home/sustainabledevelopment-goals/goal-4-qualityeducation.html (Last accessed September 2017).

30. Wolfendale, and Bastiani, J. (eds.) (2000). The contribution of parents to school effectiveness, London : David Fulton Publishers.

31. Woodward, J., Gallagher, D. and Reith, H. (2001). The instructional effectiveness of technology for students with disabilities. In : J. Woodward and L. Cuban (eds.) Technology, Curriculum and Professional Development - Adapting Schools to Meet the needs of students with disabilities. Thousand Oaks, CA: Corwin Press.

32. York, J., Vandercook, T., Macdonald, C., \& Wolff, S. (Eds.). (1989). Strategies for full inclusion. Minneapolis: University of Minnesota, Institute Oil Community Integration. 